\title{
INCIDENCIA DEL IDEAL DE MUJER DURANTE EL FRANQUISMO EN EL ÁMBITO DE LA FAMILIA Y LA ACTIVIDAD FÍSICA
}

\author{
JUAN CARlos MANRIQUe ARribas \\ Universidad de Valladolid
}

Recibido: 24/03/2014

Aceptado: 12/05/2014

\section{Resumen}

En este artículo se expone la situación que vivió la mujer durante el franquismo. Las normas sociales que le impusieron desde las instituciones dirigentes le obligaron a asumirlas como propias, únicas y verdaderas. Las relaciones entre ambos sexos quedaron así codificadas y refrendadas por un proceso propagandístico y formativo. El ideario nacionalsindicalista, transmitido por los dirigentes del Movimiento; los dogmas religiosos, transmitidos en las encíclicas y pastorales de las autoridades eclesiásticas católicas; y las proclamas de los militares establecieron el marco de actuación de la mujer. Crear una familia, traer el mayor número de hijos al mundo y educar a la prole en aquellos supuestos fueron sus objetivos prioritarios. La actividad física y deportiva, aunque debía ser un elemento liberador, también contribuyó a asentar el ideal de mujer, puesto que se mantuvo una postura rígida y autoritaria en cuanto al concepto de cuerpo femenino.

Palabras clave: Ideal de mujer, franquismo, familia, actividad física y deportiva, Sección Femenina

\begin{abstract}
This article outlines the situation that women lived in during the Franco regime. Social rules imposed by the authorities and leadership institutions forced women to accept norms and rules as their own, unique and real. The relations between genders were thus encoded and endorsed by a propagandistic and formative process. The «nacional-sindicalista» (national and pro-workers) ideology, with the leaders of «El Movimiento» (The movement) at the head, transmitted a series of religious dogma
\end{abstract}


and rules based on the military force, and established the framework which women had to fit within. The women's priorities had to be to create a family, bring more children into the world, and educate them according to those Francoist ideologies. Physical activity and sport, although it was to be a liberating element, also contributed to establish the ideal of women, since they served to establish a rigid and authoritarian approach to the concept of the female body.

Keywords: Ideal women, Francoism, family, physical activity and sport, Feminine Section 


\section{Introducción}

La mujer durante el franquismo se convirtió en un elemento de control primario por parte de la cúpula dirigente del Estado, para, a través de ella y desde su entorno de influencia, la familia, transmitir los valores y normas que el régimen político se marcó como base de su doctrina.

Así, el ideal de mujer que se conformó estuvo determinado por las consignas que cada estamento de poder aportó. Desde cualquiera de los ámbitos de influencia, militar, religioso o político, se determinó que el destino más apropiado para que su participación en la sociedad fuera efectiva era la creación de una familia. Esta estaba estructurada jerárquicamente, con unas misiones específicas según el sexo de cada integrante. Tan claro se tenía que este era el lugar preferente que debía ocupar la mujer que muchas de las leyes y órdenes que se dictaron durante este período relegaban o impedían desempeñar otras actividades laborales.

La formación se convirtió en un objetivo esencial a desarrollar por parte del departamento del único Partido político permitido, la Sección Femenina (SF) de Falange. Sus instructoras orientaron las enseñanzas del hogar hacia las escolares dándoles nociones básicas que posteriormente aplicarían en el ámbito doméstico. Los conocimientos recibidos en la enseñanza reglada, los mensajes transmitidos desde los púlpitos, las proclamas ideológicas de los políticos y el concepto de cuerpo que se transmitió a través de las actividades físico-deportivas practicadas y permitidas a la mujer contribuyeron a establecer como objetivo preferente la creación de una familia en la sociedad franquista.

\section{Pilares ideológicos que sustentaron al régimen franquista}

\subsection{Doctrina del franquismo y grupos de apoyo}

El 1 de abril de 1939 arranca un período de la historia de España que coincide con el fin del conflicto bélico. Ya durante los mismos años de la guerra, los grupos que apoyaron el golpe intentaron crear una doctrina ideológica alternativa a la posteriormente derrotada. Esta no estuvo exenta de crisis, puesto 
que hubo mucha disparidad e interna lucha ideológica ${ }^{1}$. Si en algo se pusieron de acuerdo fue en la eliminación de todo signo de identidad diferente del español, en conseguir la españolización de la población que superara las divisiones y diversidades existentes en el cuerpo social ${ }^{2}$, causantes, según los vencedores, del desastre de la guerra.

El franquismo fue una construcción ideológica que no pretendía estar supeditada a ningún estamento social o político, pero sí aspiraba a tener contentos a todos para así reafirmarse en el poder con el paso de los años. De una manera reiterada se han venido indicando los tres pilares institucionales en que se apoyó la dictadura de Franco: los militares, el Partido Único o Movimiento Nacional (basado en la doctrina de Falange Española) y la Iglesia católica.

Los militares se creían depositarios del patriotismo español, con una concepción totalmente jerarquizada de la sociedad ${ }^{3}$, en la que ellos disponían de un poder por encima del civil al considerarse ganadores de la guerra. Sus dirigentes transmitieron a la sociedad los tres apoyos básicos del buen funcionamiento que entendían debía mejorar al colectivo: unidad, autoridad y jerarquía ${ }^{4}$.

El siguiente pilar de la sociedad franquista lo constituyó la Iglesia. El soporte que brindó la Iglesia católica al bando vencedor de la guerra se gestó incluso antes de la guerra. El anticlericalismo que se respiraba durante la II República facilitó la decisión de apoyar a Franco 5 . En consecuencia, este acusado intervencionismo eclesiástico en la política franquista dio lugar al término nacionalcatolicismo ${ }^{6}$. Se concretó en un intervencionismo total en la vida de los españoles del momento, que se refrendó en la pastoral Sobre la moralidad pública que redactaron los obispos en 1956 en la Conferencia de Metropolitanos. En ella denunciaban la relajación de las costumbres, con

1. BozAL, Valeriano. El intelectual colectivo y el pueblo. Madrid, Alberto Corazón Ed., 1976, pp. 21-67.

2. DE RIQUeR, Borja: «La dictadura de Franco», en Josep Fontana y Ramón Villares (dirs.): Historia de España, vol. 3, Barcelona, Crítica/Marcial Pons, 2010, p. 31.

3. TuSELl, Javier (Dir.). Historia de España, Vol. 2. Madrid, Taurus, 2001, p. 396.

4. Sabín, José Manuel. La dictadura franquista (1936-1975). Textos y documentos. Madrid, Akal, 1997, p. 17.

5. De LlerA, Luis. «Historia de España. El régimen de Franco (1939-1975), en MoNTENEGRO, A. (Dir.): Historia de España, cap. 13, 1994, p. 96. SOUthWORTH, H. R. «La propaganda católica y la guerra civil española», Historia 16, 4 (43), noviembre (1979), p. 71. PAYNE, Stanley. El régimen de Franco, 1936-1975. Cultura y vida cotidiana. Madrid, Síntesis, 1987, p. 134.

6. IribarRen, Jesús. Papeles y memorias. Medio siglo de relaciones Iglesia-Estado en España (1936-1986). Madrid, BAC, 1993, pp. 71-73. 
una concepción rigurosísima de la moral, en especial la relacionada con la mujer: «Un feminismo absurdo aleja a muchas mujeres de su destino en pos de entretenimientos y libertades que no coinciden con el decoro y sus deberes de maternidad».

Y en tercer lugar, el pilar que más carga ideológica infundió entre los ciudadanos, el Movimiento Nacional. Este Movimiento, puesto que no había una ley de partidos que lo acogiera, asumió como propios los 26 puntos programáticos que José Antonio Primo de Rivera, fundador de la Falange, redactó.

Entre las ideas fundamentales de su doctrina se encontraba el sentido católico que debía adoptar el Nuevo Estado ${ }^{7}$, basado en el totalitarismo que repudiaba el sufragio universal y no toleraba la existencia disgregadora de los partidos políticos ${ }^{8}$, que consideraba al hombre como un conjunto de cuerpo y alma, portador de valores eternos y que sus fundamentos eran: la autoridad, la jerarquía y el orden ${ }^{9}$. En definitiva, el estilo formativo que este único Partido quiso transmitir a los ciudadanos se basaba en los siguientes conceptos: sobriedad, veracidad, alegría, cortesía, orgullo, servicio, imperativo poético y disposición combativa ${ }^{10}$; una amalgama de virtudes que definen el prototipo del hombre mitad monje, mitad soldado ${ }^{11}$. Sus aspiraciones pasaban por encuadrar y adoctrinar a toda la población ${ }^{12}$.

\subsection{Influencia de la ideología franquista en la vida de los españoles}

Tras la victoria de la guerra civil, a falta de una orientación de pensamiento definida, la necesidad de ofrecer una alternativa ideológica a la parte derrotada permitió, principalmente a Falange y a los católicos, ofrecer su ideario de conducta a todos los españoles ${ }^{13}$. Estas influencias doctrinarias fomentaron un auténtico estereotipo en la manera de ser del español. Se extendió la idea de que un buen ciudadano era aquel que demostraba una sencillez de costumbres, dignidad y una firmeza en las virtudes familiares. Eran unos valores que

7. FALANGE ESPAÑOLA. «Puntos iniciales». FE, $\mathrm{n}^{\circ}$ 1, 7 de diciembre (1933).

8. Pemartín, Julián. Teoría de la Falange. Madrid, Editora Nacional, 1942, p. 8.

9. Del Río Cisneros, Agustín. El pensamiento de José Antonio. Madrid, Ediciones del Movimiento, 1968 , p. 49.

10. Pemartín, Julián. Op. cit., pp. 29-31.

11. GONZÁLEZ AJA, Teresa. «Monje y soldado. La imagen masculina durante el franquismo». Revista Internacional de Ciencias del Deporte 1 (2005), pp. 64-83.

12. FERNÁNDEZ MirandA, Torcuato. «El Movimiento como fundamento doctrinal y la organización política del régimen español», en El hombre y la sociedad, Madrid, Doncel, 1960, p. 162.

13. INDURÁIN, Domingo. «Época contemporánea: 1939-1980», en RICO, Francisco (Dir.): Historia crítica de la literatura española, vol. 8. Barcelona, Grijalbo, 2009, pp. 29-45. 
se llevaban a gala puesto que se creía que eran los móviles naturales del pueblo hispano que se imponían ante la amenaza de otros pueblos «atosigados por los goces y disfrutes de la civilización ${ }^{14}$. Como ya indicaba José Antonio Primo de Rivera, ser español era considerarse dentro de un sentimiento, más allá de haber nacido dentro de un territorio, puesto que por el hecho de haber nacido español había que cumplir con el destino en lo universal, con un espíritu colectivo que despreciaba lo individual ${ }^{15}$.

Si España y los españoles eran considerados un todo, el comportamiento de sus ciudadanos también debía cumplir con las normas impuestas por las fuerzas de poder. Tanto en el ámbito público como en el privado se trataba de controlar todos los comportamientos, especialmente cuidado se tuvo con la moralidad femenina. En caso de que se detectara la menor desviación, sobre todo la Iglesia acudía a reparar el daño con una cruzada femenina de modestia y austeridad ${ }^{16}$.

\section{Ideal de mujer: la familia como medio de inclusión}

\subsection{Rol de la mujer y su papel en la familia}

Como ya hemos comentado, una vez finalizada la guerra civil española surgió, de modo urgente, el problema de consolidar el código de valores que había formado la moral del bando victorioso y en nombre del cual se había luchado ${ }^{17}$. España, durante prácticamente todo el franquismo, se apoyó en unos valores tradicionales, a los que se atribuía su razón de ser. Estos valores se concentraban y se desarrollaban en la familia, que se apoyaban esencialmente en la moral católica. La moral individual y la moral pública entraron de lleno en la configuración de los papeles que cada persona representaba en la sociedad ${ }^{18}$.

La mujer se vio liberada, obligada, del trabajo extrafamiliar, precisamente para consolidar y reproducir en el seno del hogar la estructura social que se había planteado. Aquí se potenciaba y reforzaba la autoridad paternal y

14. MENÉndez PidAL, Ramón. Los españoles en la historia. Madrid, Espasa Calpe, 1947, p. 161.

15. Primo de Rivera, José Antonio. Obras completas: Discursos y escritos (1922-1936). Madrid, Instituto de estudios políticos, 1976, P. 1227.

16. Resumen de las palabras del obispo de Córdoba, Adolfo Pérez Muñoz, que transmitió en una carta a Acción Católica Femenina de esa diócesis. Recogidas por el diario $A B C$, Sevilla, 1 de noviembre de 1937.

17. Martín Gaite, Carmen y SeOAne, María Cruz. «El franquismo en busca de tradición». Historia 16, no 10, febrero, 1977, p. 213.

18. CAMPS, V. Op. Cit., p. 16. 
marital con unos derechos y obligaciones que ponían a la mujer en situación claramente desfavorecedora. Su influencia se restringía al ámbito de lo doméstico y por ello se preparó una legislación que se completaba con unas leyes protectoras de la familia ${ }^{19}$ : subsidios, premios a la natalidad y a las familias numerosas; y restrictivas en el ámbito laboral: privación del plus familiar, hasta $1961^{20}$, y la prohibición de ejercer determinados trabajos ${ }^{21}$.

Por tanto, el modelo o ideal de mujer que se quiso transmitir a lo largo de todo el franquismo era aquel que respondía a una madre hacendosa, abnegada y servicial, adornada de todos los valores que el patriarcado creó para ella a lo largo de los siglos ${ }^{22}$. Se convirtió en objeto de control, pues de ella partía gran parte de la estabilidad del colectivo. Se le consideraba transmisora de los valores religiosos tanto a sus hijos como a su esposo, lo que quería decir a toda la sociedad $^{23}$. La cruzada de la moralidad fue especialmente beligerante con ella, puesto que la determinaba a estar en el hogar, sumisa al marido y a ser una máquina de procrear ${ }^{24}$. El propio José Antonio Primo de Rivera explicaba así su concepto de mujer: «Tampoco somos feministas. No entendemos que la manera de respetar a la mujer consista en sustraerla de su magnífico territorio y entregarla a funciones varoniles $»^{25}$.

Como dice $\mathrm{Camps}^{26}$, el experimento del nacionalcatolicismo generó, además de una patria católica, una moral de preceptos referidos casi exclusivamente a las relaciones con la Iglesia y con el sexo. Una moral, en consecuencia, claramente privada, cuyas virtudes fundamentales eran dos: la fe y la honestidad.

Ante este especial cuidado que se tenía para controlar el comportamiento de la mujer, el régimen franquista tuvo claro que había que devolverla a su

19. Así se estipulaba en el Fuero de los Españoles de 17 de julio de 1945.

20. Se produjo un avance jurídico tras la aprobación de la Ley de Derechos Políticos y de Trabajo de la Mujer, de 22 de julio de 1961, por la que se buscaba que la mujer accediera a los estudios universitarios y pudiera desempeñar trabajos que hasta ese momento no estaban permitidos. Sin embargo, la mujer casada seguía teniendo una obligación primaria que debía atender, trabajara o no fuera del hogar: la familia.

21. Para profundizar más en este tema aconsejamos consultar el capítulo de NASH, Mary. «Mandato biológico y cometido social: la maternidad», en Thèbaud, F. (Dir.), Historia de las mujeres. El siglo XX, vol. V, Madrid, Taurus, 1993, pp. 688-703.

22. Gallego, Ma . Teresa. Mujer, Falange y Franquismo. Madrid, Taurus, 1983, p. 107.

23. MANRIQUE, Juan Carlos. «La familia como medio de inclusión de la mujer en la sociedad franquista». Hispania Nova. Revista de Historia Contemporánea, nº 7 (2007), p. 197.

24. TUÑ́́n DE LARA, Manuel. Historia de España. Barcelona, Labor, 1988, p. 461.

25. Palabras de José Antonio Primo de Rivera en el discurso que pronunció el 28 de abril de 1935 en Don Benito (Badajoz), recogidas en el artículo titulado «Lo femenino y la Falange», en Del Rio Cisneros, Agustín. Op. Cit., 1968, p. 212.

26. CAMPS, Victoria. Virtudes públicas (Ed. $2^{a}$ ). Madrid, Espasa Calpe, 1990, p. 16.

Feminismo/s 23, junio 2014, pp. 47-68 
ámbito doméstico, del que se la había sacado al concederle una serie de derechos y privilegios durante la época de la República, a través de la ley de matrimonio civil $^{27}$ y la ley de divorcio ${ }^{28}$, además del derecho al voto y la posibilidad de ocupar puestos relevantes en la vida pública y profesional. Ahora, por el contrario, se tomaron unas decisiones que cortaron de raíz todos los avances anteriores: se suprimió la escuela mixta, se prohibió el trabajo nocturno a mujeres, se «liberó» a la mujer casada «del taller y de la fábrica» ${ }^{29}$; igualmente se les prohibió el acceso al ejercicio de profesiones liberales y otros empleos dentro de la función pública. Todo ello acompañado de una política de concesión de primas por maternidad y subsidios familiares, siempre abonables al «jefe de familia $»^{30}$.

\subsection{Canales de formación de la mujer para desarrollar correctamente su labor en la familia}

Para lograr una formación que se ajustara al estereotipo de mujer que los dirigentes franquistas se habían marcado se utilizaron dos canales especialmente. Por un lado, el que ofrecía la SF de Falange, una de las Delegaciones Nacionales de masas que trató de encuadrar y adoctrinar a todas las mujeres españolas. Su departamento o regiduría de Formación se dedicó a transmitir la ideología nacionalsindicalista. La otra regiduría, la de Cultura, se interesaba por la educación doméstica, con la creación de Escuelas de Hogar, la alfabetización, la música y el folclore.

El canal de transmisión más utilizado fue la escuela, la enseñanza reglada y oficial, a través de la inclusión de materias que eran impartidas por personal convenientemente formado por los órganos de poder político. Las Enseñanzas del Hogar, la Formación del Espíritu Nacional o la Educación Física fueron impartidas por instructoras de la SF que participaban del sistema educativo, pero que no pertenecían al Ministerio de Educación ${ }^{31}$. Por supuesto, estas novedades en el programa formativo reglado rompieron con las transformaciones innovadoras que los gobiernos republicanos introdujeron, como por

27. Por la Ley de 12 de marzo de 1938 se derogó la Ley de 28 de junio de 1932, lo que supuso la abolición del matrimonio civil.

28. Por la Ley de 23 de septiembre de 1939 se derogó la Ley de divorcio de 1932.

29. Título II del Fuero del Trabajo (9 de marzo de 1938).

30. MoraGA, $\mathrm{M}^{a}$ Ángeles. «Notas sobre la situación jurídica de la mujer en el franquismo». Feminismo/s 12, (2008), p. 230.

31. MANRiQUe, Juan Carlos; LóPEZ, Víctor Manuel; TORREGo, Luis Mariano y MONJAS, Roberto. «La labor formativa desarrollada por la Sección Femenina de la Falange en la preparación de sus mandos e instructoras durante el período franquista». Historia de la Educación. Revista Interuniversitaria, 27 (2008), pp.347-365. 
ejemplo fueron: el plan de alfabetización de las personas adultas, especialmente de las mujeres, la coeducación ${ }^{32}$, la creación de escuelas e institutos o la extensión de las Misiones Pedagógicas ${ }^{33}$.

Precisamente las Enseñanzas del Hogar fue quizás el rasgo más distintivo del sistema educativo durante el franquismo, puesto que se transmitieron mensajes orientados solo hacia las mujeres. Los contenidos que abarcaban desplegaban un amplio abanico de actividades como: los cuidados de la vivienda y de los muebles, la limpieza del hogar, la iluminación, la decoración, las ropas, el planchado, la alimentación, la conservación de los alimentos, disponer y servir la mesa, gestionar el presupuesto familiar, cuidar de la salud de los miembros de la familia, la costura, las relaciones de pareja y con los hijos, la confección de prendas de vestir e incluso la actividad física en el hogar. Todo ello con la finalidad de «proporcionar los conocimientos básicos que debe poseer toda mujer, con el fin de estar capacitada para cumplir su misión como ama de casa» ${ }^{34}$.

La formación de la mujer, desde la más temprana edad, debía tener presente que su educación cumplía con los conocimientos relativos a su condición. El hogar y su familia era el contexto físico y espiritual donde desempeñaba sus labores específicas de género.

\subsection{La maternidad como objetivo prioritario dentro de la familia}

Con la paz, el gobierno franquista no tardó en introducir medidas para luchar contra la mortalidad infantil. España debía recuperarse de las miles de muertes que generó el conflicto, sobre todo las masculinas. Así, se quiso potenciar la regeneración de la población con la llegada al mundo de nuevos ciudadanos que pudieran poner en funcionamiento el engranaje económico y social de España en los años sucesivos. Con este planteamiento inicial se dio un especial énfasis a la función procreadora de la mujer. La propia SF centró su dedicación a las tareas asistenciales, sobre todo a la lucha contra la mortalidad infantil, dada la incapacidad del Estado para ofrecer unos servicios sanitarios dignos y adecuados. Pero no sólo se alababa la condición fisiológica, sino que su misión iba más allá, ya que se estimaba era el fundamento primario para sustentar el entramado socio-ideológico del régimen.

32. Tras la Orden Ministerial del 1 de mayo de 1939 se prohibió el sistema pedagógico de coeducación en las escuelas primarias.

33. FLECHA, Consuelo. «La Segundo República, las mujeres y la educación», en SÁNCHEZ, Elena (Ed.): Las maestras de la República (2ª Ed.), Madrid, Catarata, 2013, pp. 36-37.

34. Bartina, Teresa. Ama. Resumen de Economía Doméstica. Madrid-Gerona, Dalmáu, 1964 (edición especial para el Ministerio de Educación Nacional), p. 3.

Feminismo/s 23, junio 2014, pp. 47-68 
La propia Pilar Primo de Rivera, primera y única Delegada Nacional de la SF, en su discurso dirigido a las mujeres que se congregaron en Medina del Campo, en mayo de 1939 como homenaje a Franco, ya adelantó lo que esperaba de las mujeres españolas con respecto al cuidado de los hijos: «Enseñaremos a las mujeres el cuidado de los hijos, porque no tiene perdón que se mueran por ignorancia tantos niños que son siervos de Dios y futuros soldados de España». Se tenía claro que lo que se aprendía en el hogar no se olvidaría jamás, puesto que se entendía que la mujer era la que transmitía la continuidad de las cosas, la que preparaba al nuevo ser para el futuro ${ }^{35}$. Se trataba de configurar un tipo de mujer que tuviera asimilada su doble función de madre ${ }^{36}$, por supuesto antes se había convertido en esposa, y posteriormente en transmisora de los ideales nacionalcatólicos y nacionalsindicalistas.

Tener como único fin traer nuevos seres al mundo fue considerado un precepto divino que la mujer, dentro del matrimonio, tenía que llegar a conseguir. Los fundamentos en los que se basaba esta misión tenían un doble componente religioso y político. El primero tuvo una mayor relevancia, ya que a la mujer española se la consideraba católica, apostólica y romana, mientras no se demostrase lo contrario; puesto que por ambiente, educación, tradición familiar y rutina sentía y vivía el catolicismo ${ }^{37}$.

El cometido social al que debía atender la mujer era diferente al del hombre, pero a la vez complementario: concebir hijos y perpetuar la especie ${ }^{38}$. Incluso aquellas mujeres que no tenían hijos podían desarrollar su misión social de la maternidad con «su servicio a los hijos de los demás» ${ }^{39}$. Todo este esfuerzo que debía realizar la mujer, siempre dentro de la familia, estaba destinado a conseguir una robustez de la raza ${ }^{40}$, para de este modo constituir lo que denominaba la doctrina falangista la fuerza, la riqueza y el orgullo

35. DELEGACIÓN NACIONAL DE LA SECCIÓN FEMENINA DE FET Y DE LAS JONS. «Editorial», revista Teresa, julio de 1958.

36. MARTínEZ, Francisco Javier y AlFONSO, José Manuel. «Tardes de enseñanza y parroquia: el adoctrinamiento de las niñas en la España franquista a través de las revistas bazar y tin tan (1947-1957)». El futuro del pasado 14 (2013), p. 230.

37. Resumen de las palabras escritas por el Padre FrAnCO, Vicente. Revista Teresa, agosto (1961), SF DE FET y DE LAS JONS.

38. PÉrez DE URbel, Fray Justo. III Consejo Nacional de SF de FET y de las JONS, celebrado en las provincias de Zamora y León (1939), SF DE FET y DE LAS JONS.

39. NASH, Mary. Op. Cit., p. 629.

40. Vallejo Nágera creía, por ejemplo, que el individuo poseía cualidades heredadas, algunas de la familia y otras exclusivas de la raza. VALLEjo NÁGERA, Antonio. «Higiene psíquica de la raza», en Memoria resumen de las tareas científicas del I Congreso Nacional de Educación Física, Madrid, Jesús lópez, 1943, p. 243. 
de los pueblos ${ }^{41}$. El culto a la madre se hizo extensivo a toda la sociedad, reconociendo que fueron ellas las que habían sacado adelante a los hijos en un ambiente desalentador, sin perder su dignidad. En estas circunstancias se intensificó el mito de «la santa madre»" ${ }^{42}$ que renunciaba a todo desahogo placentero con vocación de «ascesis religiosa» ${ }^{43}$.

Ante este gran condicionamiento que se ejercía sobre la mujer, advertimos algunas incongruencias entre quienes dirigían la SF. Sus dirigentes establecieron en sus estatutos que la mujer casada dejaba de ejercer sus obligaciones laborales. Esto supuso que muchas de ellas no se casaran o lo hicieran a edades muy tardías. Ellas que manifestaban constantemente la función procreadora como la base de existir de la mujer dejaron de cumplir tal precepto, aunque ellas siempre alegaban que eran capaces de dejar el hogar sin perder su feminidad ${ }^{44}$.

\section{La mujer y su misión en el hogar familiar}

En el ámbito familiar se impuso un modelo de sociedad patriarcal basado en el predominio de la familia cristiana tradicional que preconizaba la total sumisión de la mujer al hombre. La nueva moral oficial convertía a la mujer en esposa y madre, dificultando su acceso a la educación y a la vida profesional. En la familia, cada uno de sus miembros adquiría unos roles y misiones dentro de la misma, que debían contribuir a conseguir una situación de felicidad y bienestar. En este caso, el hombre, el marido, era el encargado de traer los bienes materiales, mientras que la mujer tenía reservado un lugar secundario, relacionado con el aspecto asistencial. Así lo proponía la Delegada Nacional de la SF con motivo del II Consejo Nacional de la Organización celebrado en Segovia en 193845: «El buen Estado nacional-sindicalista descansa en la familia, y él será fuerte si la mujer, en la casa, es sana, fecunda, laboriosa y alegre». Y el propio Franco, en aquel mayo de 1939, ante miles de mujeres de la SF, alentó cuál debía ser la obligación de la Organización y, por tanto, de la mujer,

41. Molinero, Carmen. «Silencio e invisibilidad: la mujer durante el primer franquismo». Revista de Occidente 223 (1999), 63-82.

42. Se instauró el día de la madre el 8 de diciembre, el mismo día que se celebraba la festividad de la Inmaculada Concepción, imagen religiosa a imitar por todas las mujeres de la época.

43. MARTín GAITE, Carmen. Usos amorosos de la postguerra española. Barcelona, Anagrama, 1987, p. 107.

44. RichmOND, Kathleen. Las mujeres en el fascismo español. La Sección Femenina de la Falange, 1934-1959. Madrid, Alianza Ensayo, 2004, p. 235.

45. Primo De Rivera, Pilar. Discursos, Circulares y Escritos. Madrid, Gráficas Afrodisio Aguado, 1942, p. 7

Feminismo/s 23, junio 2014, pp. 47-68 
«os queda la reconquista del hogar, formar al niño y a la mujer española, hacer a las mujeres sanas, fuertes e independientes ${ }^{46}$.

\subsection{El hogar familiar destino de la mujer}

La nueva legislación laboral ${ }^{47}$, bastante discriminatoria para la mujer, fomentó que la familia se convirtiera en un espacio único para desarrollar las capacidades del sexo femenino. En 1939 se limitó a las casadas la inscripción en los registros de colocación, se hizo necesario el permiso del marido o del padre para ser contratada, puesto que según el artículo 60 del Código civil, «el marido es el representante de su mujer». Desde 1942 numerosas ordenanzas laborales establecieron que al contraer matrimonio la mujer debía abandonar su trabajo, siendo compensada con una dote. Y a través de la Orden reguladora del «plus familiar», de 19 de julio de 1945, se indicaba que dicha ayuda económica lograría «fortalecer la familia y su tradición cristiana, la sociedad perfecta y cimiento de la Nación».

Con estos planteamientos se fue haciendo una propaganda positiva de todo aquello que dignificara el trabajo en el hogar, como medio de realización personal de la mujer. Tanto desde el ámbito religioso como desde el político se argumentaba la predisposición a ocupar ese lugar que Dios y la Patria la había preparado ${ }^{48}$. La familia se convirtió en la columna vertebral del sistema social, basada en el matrimonio ${ }^{49}$ indisoluble monógamo, aunque claramente desequilibrado en cuanto a la influencia efectiva que ejercía cada componente en virtud de su sexo. La mujer, cuando pasaba a formar parte de la familia, pasaba también a depender de la potestad del marido, como antes dependió de la potestad de su padre o de algún hermano, en caso de que aquel hubiera fallecido. Exponemos ahora dos argumentos realizados desde representantes

46. Franco Bahamonde, Francisco: «Discurso a la Sección Femenina en el Acto de Homenaje al Caudillo y al Ejército» (Medina del Campo, 30 de mayo de 1939), en Palabras del Caudillo: 19 abril de 1937 a 7 de diciembre 1942. Madrid, Editora Nacional, 1943, pp. 129-133. Cita recogida también en AMADOR, Pilar. «La mujer es el mensaje. los coros y danzas de Sección Femenina en Hispanoamérica», Feminismo/s, 2 (2003), pp. 103. SuÁrez, Luis. Crónica de la Sección Femenina y su tiempo. Madrid, Asociación Nueva Andadura, p. 101.

47. Para consultar la evolución jurídica de la mujer durante el franquismo recomendados el artículo de Moraga, $\mathrm{M}^{a}$ Ângeles. Op. Cit., pp. 229-252.

48. MANRIQUE, Juan Carlos. «La familia como medio de inclusión de la mujer en la sociedad franquista». Hispania Nova. Revista de Historia Contemporánea, no 7 (2007), p. 208.

49. Según palabras de Pilar Primo de Rivera: [el matrimonio] es el cauce normal por el que toda mujer debería encauzar su vida». Recogido por ZaVALA, José María. La pasión de Pilar Primo de Rivera. Barcelona, Plaza \& Janés, 2013, p. 430. 
de los dos pilares más importantes que influyeron en la conformación social del franquismo: la Iglesia y Falange, a través de su SF.

El padre es cabeza de la mujer como Cristo es cabeza de la Iglesia. [...] La esposa tiene el carácter de auxiliar [...] El hombre tiene por regla general, mayor vigor físico y mental [...] en todas las naciones, salvajes y civilizadas, la autoridad doméstica corresponde al padre ${ }^{50}$.

La jerarquía familiar es el padre. No le proviene al padre la autoridad de su fuerza física, o de la superioridad social o económica. Le proviene directamente de Dios. De esta autoridad se dice que es de «institución divina». Así, el padre es, en la familia, el representante de la paterna autoridad de Dios. Y la madre recibe la autoridad por participación en la del esposo ${ }^{51}$.

A pesar de los cambios que se fueron sucediendo a lo largo de los años que duró el franquismo, estos valores de la familia se mantuvieron a pesar de las influencias que provenían de fuera de España. La propia Pilar Primo de Rivera, a pesar del viraje producido a partir de los años sesenta y principios de los setenta, todavía pensaba que se debían cumplir los fines que la mujer contraía al crear una familia. Las leyes que se promulgaron, sobre todo la de $1961^{52}$, a favor de una mayor equiparación laboral con el hombre y una participación activa en los asuntos sociales, no fueron considerados asuntos primordiales para la SF, puesto que la mujer no podía olvidarse que «[...] tiene (la mujer) también unos deberes familiares que, según en qué momentos de la vida, deben primar sobre cualquier otra consideración y donde alcanza su verdadera realización $»^{53}$.

Pasaron los años, pero el discurso no varió sustancialmente. La SF seguía fiel a sus principios. Para ellas, «cuanto mejor gobernada esté la casa, más feliz será la familia» ${ }^{54}$, y a través de este servicio a la familia, se servirá mejor a la Patria.

50. Palabras emitidas por el cardenal Gomá, recogidas por ABELLA, Rafael. La vida cotidiana bajo el Régimen de Franco. Madrid, Temas de Hoy, 1996, p. 366.

51. SF DE FET Y DE LAS JONS. Formación Politico-Social. Quinto curso de Bachillerato. Madrid, SF de FET y de las JONS, 1965, p. 47.

52. Ley 56/1961, de 22 de julio, de Derechos políticos, Profesionales y de Trabajo de la Mujer.

53. Primo de Rivera, Pilar. XXVII Consejo Nacional de la SF en Logroño, mayo, 1974. Madrid, SF de FET y de las JONS, p. 4.

54. SF DE FET Y DE LAS JONS. Formación Político-Social. Primer curso de Bachillerato. Madrid, Delegación Nacional de la SF de FET y de las JONS, 1962, p. 67.

Feminismo/s 23, junio 2014, pp. 47-68 


\section{Condicionamientos para realizar actividad física y deportiva según el modelo de mujer}

Tras los argumentos expuestos anteriormente, durante el franquismo se fueron dando las claves para crear unos estereotipos que trababan de simplificar la realidad. De este modo se crearon unos estereotipos que servían para defender la posición de algunos grupos sociales y así defender su posición dominante sobre otros ${ }^{55}$. En el caso de la mujer, los grupos de presión buscaron, sobre todo con estudios de medicina o con mensajes de las escrituras sagradas, sustentar sus teorías que convergían en una supuesta inferioridad tanto física como intelectual de la mujer.

En este contexto, la SF de Falange tuvo la misión de formar integralmente a la mujer. Ya hemos explicado que lo más importante para esta Organización era prepararla convenientemente para desempeñar su papel de madre y esposa en el seno de la familia. Sin embargo, esta formación no se estimaba completa si no se le añadía el componente físico y deportivo. Pilar Primo de Rivera estaba convencida de que la educación física mejoraría la salud y el bienestar de las mujeres. Sin embargo, la sociedad no estaba preparada para verla en público realizando actividades físicas ${ }^{56}$.

Durante el período de la República, el deporte se convirtió para muchas mujeres en «una forma de emancipación y un símbolo de independencia y superación cultural ${ }^{57}$, aunque restringido al ámbito urbano y todavía muy limitado ${ }^{58}$. Posteriormente, la SF, institución encargada en exclusiva de poner en marcha un plan específico físico-deportivo entre las mujeres, tuvo que hacer frente a los condicionamientos sociales que consideraban indecorosa su participación en público ${ }^{59}$. Si la mujer estaba obligada a desarrollar sus actividades en el ámbito privado, le iba a resultar especialmente difícil practicar el

55. HuicI, Carmen. «Estereotipos», en Morales, Francisco J. y Huici, C. (Coords.). Psicología social. Madrid, McGraw-Hill, 1996, p. 76.

56. REGIDURÍA CENTRAL DE EDUCACIÓN FÍSICA. La actividad física y deportiva en la mujer, Real Academia de la Historia, Archivo de la Asociación Nueva Andadura, carpeta 41, doc. 3.

57. RIVERO, Antonio. Deporte y modernización. Madrid, Comunidad de Madrid, 2003, p. 208.

58. Es destacable la creación del Club Femení i d'Esports de Barcelona, que funcionó entre 1928 y 1936, una entidad fundada, gestionada y dirigida por y para mujeres, que abrió las puertas a las nuevas formas de sociabilidad femenina desarrolladas durante el período republicano. PujAdAS, Xavier. «Del barrio al estadio. Deporte, mujeres y clases populares en la Segunda República, 1931-1936, en PUJADAS, Xavier: Atletas y ciudadanos. Historia social del deporte en España 1870-2010, Madrid, Alianza Editorial, 2011, p. 152.

59. Primo De Rivera, Pilar. Recuerdos de una vida. Madrid, Dyrsa, 1983, p. 279. 
deporte en espacios abiertos a la opinión pública. Aunque en cualquier contexto se manifestaba la conveniencia de realizar ejercicio físico, las jerarquías sociales jugaron un papel ambivalente, a veces contradictorio, ya que apoyaban tales prácticas pero siempre se ponía algún tipo de restricción.

\subsection{Postura científico-médica}

La Delegada Nacional de SF, aconsejada por el asesor nacional en esta materia, Luis Agosti ${ }^{60}$, entendía la cultura del cuerpo no como puro entretenimiento, sino que estaba más cercana a la tendencia orientada a mejorar la salud de las mujeres ${ }^{61}$. Los planteamientos iniciales a la hora de establecer un programa de actuación relativo al uso apropiado del cuerpo femenino estuvieron condicionados por los argumentos provenientes de la clase médica. Estas explicaciones se basaban en una cuestión categórica y obvia, puesto que se apoyaban en las diferencias fisiológicas entre los cuerpos del hombre y la mujer. En este sentido, fueron numerosos los ejemplos, en forma de ensayos ${ }^{62}$ y dictámenes, que cuestionaban ciertas prácticas físicas porque podían poner en peligro la misión biológica fundamental de la mujer, la maternidad.

Aunque se decía que el ejercicio físico servía como medicina preventiva al servicio de la salud, el caso es que estos supuestos científico-médicos contribuían a reforzar el estereotipo de género femenino, al que tildaban de frágil y delicado; por lo tanto, poco capaz de realizar actividades de gran exigencia física. El propio Agosti ${ }^{63}$ estableció los períodos críticos en los que la mujer tenía muy comprometido su deseo de realizar cualquier tipo de práctica física, como por ejemplo durante el período de la pubertad o durante el ciclo menstrual. Se establecieron una serie de actividades que eran adecuadas para el cuerpo de la mujer: la gimnasia, la danza (clásica y regional) y el ritmo; además de otros deportes que se fueron incluyendo en la lista en diferentes años: natación (1938), hockey, tenis y baloncesto (1939), balón a mano a 7 y a 11 (1940), balonvolea (1953); y desaconsejaron otros por ser demasiado viriles y extenuantes: fútbol, boxeo, rugby o el atletismo, que no se permitió hasta

60. Era médico y había sido campeón nacional de lanzamiento de jabalina antes de la guerra. Es un hecho significativo, que buscan a un hombre para que asesore a las regidoras de Educación Física, pues estas no poseían los conocimientos científicos adecuados para ponerla en funcionamiento.

61. SF DE FET Y DE LAS JONS. «Consigna». Medina, nº 10, julio, 1941, p. 12.

62. MARAÑón, Gregorio. Tres ensayos sobre la vida sexual: Sexo, trabajo y deporte; maternidad y feminismo; educación sexual y diferenciación sexual. Madrid, Biblioteca Nueva, 1926, pp. 49 y 56.

63. Agosti, Luis. Gimnasia Educativa. Madrid, Ex Libris, 1963 (1948, $1^{\text {a }}$ Ed.), pp. 710 y 719.

Feminismo/s 23, junio 2014, pp. 47-68 
$1961^{64}$. Por supuesto, estas actividades se entendían se podían realizar antes de que se formara una familia, pues aquí ya se priorizaban otros cometidos.

\subsection{La postura religiosa}

Los planteamientos religiosos, que entienden a la persona bajo el dualismo mente y cuerpo, criticaban que el cuerpo de la mujer deportista lograra ser motivo de exhibiciones que la podían llevar al pecado. La SF volvió a hacer «encaje de bolillos» para no salirse de las directrices que dictaban los asesores religiosos, ya que al proponer la actividad físico-deportiva para las mujeres podía entrar en conflicto con el ideario ultracatólico. De ahí que siempre se considerara el deporte con un «fondo espiritual ${ }^{65}$, en el que a través del cuidado de su cuerpo obtenía de él «la salvación de su propia alma y de la mayor gloria de Dios» ${ }^{66}$.

La Iglesia, además de dar esta idea ascética de la actividad física, también estuvo vigilante en todo lo que se refería a las normas de funcionamiento en los diferentes campeonatos (horarios supeditados a las horas de culto en días de fiesta), en la manera de vestir en las clases de EF (uso de los pololos o faldas-pantalón poco prácticas para el ejercicio físico) o en los campeonatos de natación (uso del albornoz siempre que no se estuviera en el agua). Unas normas que impusieron un estilo que no atentaba contra lo que las jerarquías religiosas denominaban las buenas costumbres y el estilo ${ }^{67}$. Como vemos, pocos alicientes tenían las chicas por practicar una actividad deportiva que estaba sujeta a tantas normas de comportamiento. Las jóvenes deportistas estaban muy controladas por la supervisión de la ciudadanía y de las autoridades eclesiásticas. Ante este estricto control, poco margen de maniobra le quedaba a la mujer casada, que en su ámbito privado de la familia pocas alternativas se le dejaban para practicar alguna actividad deportiva.

64. MANRIQUE, Juan Carlos. «Factores que determinaron una Educación Física de género durante el franquismo». Apunts. Educación Física y Deportes, 98, $4^{\circ}$ trimestre, (2009), p. 11.

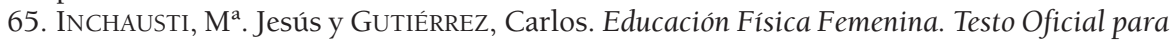
las Escuela de Magisterio. Madrid, SF de FET y de las JONS, 1955, p. 12.

66. SF DE FET Y DE LAS JONS. Oposiciones de Magisterio. Educación Física. Madrid, SF de FET y de las JONS, 1959, p. 140.

67. SF DE FET y DE LAS JONS. Historia y Misión. Madrid, SF de FET y de las JONS, 1951, p. 98. 


\subsection{La postura política}

El ciudadano español, en un Estado autoritario como el franquismo, estuvo sometido a los dictámenes de la clase política dirigente. El objetivo más importante que se planteaba el gobierno era el que cada individuo cumpliera con los cometidos que se le encomendaban en función de su condición. En el caso de las mujeres, su cumplimiento con la patria se centraba en traer hijos sanos al mundo y educarlos en las doctrinas nacionalsindicalistas ${ }^{68}$. Por supuesto, siempre dentro del matrimonio canónico y en un entorno familiar cristiano.

La práctica de ejercicio físico para la mujer estaba recomendada para fortalecer su cuerpo y traer el mayor número de vástagos que pudieran defender con garantías a la Patria. Bajo los presupuestos de fortaleza física que debía conseguir cualquier ciudadano, se instauró como objetivo político una educación física y deportiva obligatoria para todos, aunque regida por la separación de sexos y planteada como proyección del régimen ${ }^{69}$.

El deporte era entendido como una práctica selectiva llevada a cabo por los mejor dotados física y mentalmente, para así poder realizar los servicios que requiere la «gran empresa espiritual» de regir una nación. El deporte era controlado por el Estado, especialmente el dirigido a la juventud, que se constituyó en la auténtica cantera de ciudadanos convenientemente adoctrinados. La EF se convirtió en una de las enseñanzas que la mujer estaba obligada a recibir, puesto que a través de ella pariría hijos más fuertes y sanos, lo que mejoraría la raza y el futuro de la Nación. Esto es lo que la SF esperaba de la actividad física para la mujer: «La higiene, la gimnasia y el deporte hacen de cada una de nosotras esa mujer sana y limpia moralmente que el Estado quiere para madre de sus hombres del porvenir» ${ }^{70}$.

Así que la mujer casada, aunque se le indicaba que tenía un gran compromiso con la sociedad al traer niños sanos y fuertes, tenía pocas oportunidades de volver a practicar la actividad deportiva que realizó en sus años previos al matrimonio, salvo que se sintiera realizada en el cumplimiento de sus rutinas domésticas: barriendo, fregando los suelos, sacudiendo las alfombras o realizando la compra. En el siguiente párrafo, fechado a finales de los sesenta,

68. CADENAS, Cándida. «La educación física femenina», en Delegación Nacional de Deportes: Memoria-resumen de las tareas científicas del I congreso Nacional de Educación Física, Madrid, Jesús López, 1943, p. 438.

69. MANRIQUE, Juan Carlos. «Juventud, Deporte y Falangismo. El Frente de Juventudes, la Sección Femenina y los deportes del 'Movimiento', en Pujadas, Xavier. Op. Cit., p. 265.

70. SF de FET y de las JONS. «Plan del ama de casa para 1941». Y, (1941), Madrid, SF de FET y de las JONS. 
se expresaba el concepto de actividad física que debía desarrollar la mujer casada $^{71}$ :

Una mujer que tenga que atender a las faenas domésticas con toda regularidad tiene ocasión de hacer tanta gimnasia como no lo hará nunca si, verdaderamente, trabajase fuera de su casa. Solamente la limpieza y el abrillantamiento de los pavimentos, quitar el polvo de los sitios altos, limpiar cristales, sacudir los trajes, se darán cuenta de que se realizan tantos movimientos de cultura física que aun cuando no tienen como finalidad la estética del cuerpo, son igualmente eficacísimos precisamente para este fin.

\section{Conclusiones}

El Franquismo es un período histórico que estableció un marco de relaciones de género influidas por unos valores emanados desde los diferentes ámbitos de poder. Durante casi cuarenta años las instituciones gubernamentales, el Movimiento, la Iglesia y los militares, trataron de establecer las posiciones que cada individuo debía asumir en la sociedad. En el caso de la mujer, se instaló el estereotipo de la mujer sumisa, obediente y disciplinada abocada a cumplir con su destino de la maternidad en un hogar convenientemente preparado para ocupar en él un papel secundario. Tanto las leyes que se fueron aprobando, como los mensajes desde los púlpitos y algunos estudios científicomédicos convergieron en una imagen de la mujer destinada a cumplir con su rol de género más tradicional y conservador.

La sociedad española se fundamentó en la familia como célula organizativa primaria y natural de la población, declarada como tal en la primera de las Leyes Fundamentales dictada, el Fuero del Trabajo de 1938. La mujer adquiere un papel secundario en esta sociedad, pero por el contrario se la quiere dignificar a través de la influencia que ésta demuestra en el campo de las relaciones familiares y en la transmisión de modelos y valores formativos relacionados con la ideología, la religión, el civismo, etc.

El sistema educativo tuvo muy presente la separación de sexos a la hora de recibir la formación académica correspondiente. En el caso de las chicas, entre las enseñanzas que recibieron se encontraban algunas que las orientaban hacia su destino fundamental en la sociedad franquista: la creación de una familia. Así, desde la escuela ya se recibían nociones sobre corte y confección, economía doméstica o elementales cuidados pediátricos. Por supuesto, siempre teniendo como referencia la carga ideológica falangista y los comunicados católicos que condicionaban la manera de entender las relaciones entre

71. Clot, Emilio. Gimnasia Femenina. Barcelona, Editorial Juventud, 1966, Prólogo.

Feminismo/s 23, junio 2014, pp. 47-68 
los miembros que componían el hogar. En este sentido, la SF adquirió un peso muy importante como gestora y orientadora de estos conocimientos en el ámbito educativo. Sus instructoras fueron las únicas preparadas para llevar a cabo este cometido, por encargo oficial de las jerarquías gubernamentales.

El cuerpo de la mujer es apreciado por ser fuente de vida. La procreación se convierte en su principal misión, por lo que todo el cuidado que preste a su cuerpo debe orientarse a conseguir hijos sanos y fuertes. Nunca lo debe utilizar para exhibirlo ni para disfrutar de él, como en el caso de la práctica de la actividad física y el deporte. Una actividad físico-deportiva que se debe ajustar al modelo de mujer imperante, más plástica y expresiva que la competitiva y agresiva del modelo masculino. Precisamente esta actividad es considerada de especial relevancia para conseguir traer hijos sanos que contribuyan a perpetuar la raza y hacer ciudadanos mejor preparados y así defender mejor los intereses de la Nación.

La familia se entendió como el entorno natural donde la mujer se desenvolvía mejor. Su preparación y formación, los mensajes recriminatorios por parte de los representantes de la Iglesia si no cumplía con la maternidad, la evaluación permanente que la ciudadanía ejercía sobre sus actos y su actuación pública o la influencia doctrinal para servir a la Patria contribuyeron a crear un estado de opinión que determinó que la familia era la mejor manera de que la mujer se sintiera integrada dentro de la sociedad franquista.

\section{Referencias bibliográficas}

Abella, Rafael. La vida cotidiana bajo el Régimen de Franco. Madrid, Temas de Hoy, 1996, p. 366.

Agosti, Luis. Gimnasia Educativa. Madrid, Ex Libris, 1963 (1948, 1ª Ed.), pp. 710 y 719.

AMADOR, Pilar. «La mujer es el mensaje. Los coros y danzas de Sección Femenina en Hispanoamérica». Feminismo/s, 2 (2003), pp. 103.

Bartina, Teresa. Ama. Resumen de Economía Doméstica. Madrid-Gerona, Dalmáu, 1964 (edición especial para el Ministerio de Educación Nacional), p. 3.

BozAL, Valeriano. El intelectual colectivo y el pueblo. Madrid, Alberto Corazón Ed., 1976, pp. 21-67.

CADENAS, Cándida. «La educación física femenina», en Delegación Nacional de Deportes, Memoria-resumen de las tareas científicas del I congreso Nacional de Educación Física, Madrid, Jesús López, 1943, p. 438.

CAMPS, Victoria. Virtudes públicas (Ed. $2^{a}$ ). Madrid, Espasa Calpe, 1990, p. 16.

Clot, Emilio. Gimnasia Femenina. Barcelona, Editorial Juventud, 1966, Prólogo.

DE LLERA, Luis: «Historia de España. El régimen de Franco (1939-1975), en MoNTenegro, A. (Dir.) Historia de España, cap. 13, Madrid, Gredos, 1994, p. 96. 
DE RiQUeR, Borja: «La dictadura de Franco», en Josep Fontana y Ramón Villares (dirs.): Historia de España, vol. 3, Barcelona, Crítica/Marcial Pons, 2010, p. 31.

Dels Río Cineros, Agustín. El pensamiento de José Antonio. Madrid, Ediciones del Movimiento, 1968, p. 49.

DELEGACIÓN NACIONAL DE LA SECCIÓN FEMENINA DE FET Y DE LAS JONS. «Editorial». Revista Teresa, julio de 1958.

FALANGE ESPAÑOLA. «Puntos iniciales». FE, nº 1, 7 de diciembre,1933.

FERNÁNDEZ MiRANDA, Torcuato. «El Movimiento como fundamento doctrinal y la organización política del régimen español», en El hombre y la sociedad, 1960, Madrid, Doncel, p. 162.

FLECHA, Consuelo: «La Segundo República, las mujeres y la educación», en SÁNCHEZ, Elena (Ed.): Las maestras de la República (2ª Ed.), Madrid, Catarata, 2013, pp. 36-37.

FRANCO, Vicente. Revista Teresa, agosto, SF de FET y de las JONS.

FUERO DE LOS ESPAÑOLES, de 17 de julio de 1945.

FUERO DEL TRABAJO, Título II, de 9 de marzo de 1938.

Gallego, Ma . Teresa. Mujer, Falange y Franquismo. Madrid, Taurus, 1983, p. 107.

GONZÁlEZ AJA, Teresa. «Monje y soldado. La imagen masculina durante el franquismo». Revista Internacional de Ciencias del Deporte 1 (2005), pp. 64-83.

GonZÁlez BALAdO, José Luis. «La crisis del nacionalsindicalismo». Historia 16, $n^{\circ}$ 9, enero (1977).

Huici, Carmen. «Estereotipos», en Morales, Francisco J. y Huici, C. (Coords.): Psicología social, Madrid, McGraw-Hill, 1996, p. 76.

InCHAUsti, Ma . Jesús y GutiÉRREZ, Carlos. Educación Física Femenina. Testo Oficial para las Escuela de Magisterio. Madrid, SF de FET y de las JONS, 1955, p. 12.

INDURÁIN, Domingo. «Época contemporánea: 1939-1980». En RICO, Francisco

(Dir.): Historia crítica de la literatura española, vol. 8, Barcelona, Grijalbo, 2009, pp. 29-45.

IRIBARREN, Jesús. Papeles y memorias. Medio siglo de relaciones Iglesia-Estado en España (1936-1986), Madrid, BAC, 1993, pp. 71-73.

Ley 56/1961, de 22 de julio, de Derechos políticos, Profesionales y de Trabajo de la Mujer.

Ley de 12 de marzo de 1938, por la que se derogó la Ley de 28 de junio de 1932, lo que supuso la abolición del matrimonio civil.

Ley de 23 de septiembre de 1939, por la que se derogó la Ley de divorcio de 1932. Ley de Derechos Políticos y de Trabajo de la Mujer, de 22 de julio de 1961.

MANRIQUE, Juan Carlos. «Factores que determinaron una Educación Física de género durante el franquismo». Apunts. Educación Física y Deportes, 98, $4^{\circ}$ trimestre (2009), p. 11. 
- «Juventud, Deporte y Falangismo. El Frente de Juventudes, la Sección Femenina y los deportes del 'Movimiento', en PUJADAS, Xavier: Atletas y ciudadanos. Historia social del deporte en España 1870-2010, Madrid, Alianza Editorial, 2011, p. 265.

- «La familia como medio de inclusión de la mujer en la sociedad franquista». Hispania Nova. Revista de Historia Contemporánea, no 7, (2007), pp. 197 y 208.

MANRiQUe, Juan Carlos; LóPEZ, Víctor Manuel; TORREGO, Luis Mariano y MONJAS, Roberto. «La labor formativa desarrollada por la Sección Femenina de la Falange en la preparación de sus mandos e instructoras durante el período franquista». Historia de la Educación. Revista Interuniversitaria, 27, 2009, pp.347-365.

MARAÑón, Gregorio. Tres ensayos sobre la vida sexual: Sexo, trabajo y deporte; maternidad y feminismo; educación sexual y diferenciación sexual. Madrid, Biblioteca Nueva, 1926, pp. 49 y 56.

Martín Gaite, Carmen y SeOANE, María Cruz. «El franquismo en busca de tradición». Historia 16, nº 10, febrero, 1977, p. 213.

MARTín GAITE, Carmen. Usos amorosos de la postguerra española. Barcelona, Anagrama, 1987, p. 107.

MarTíneZ, Francisco Javier y AlFonso, José Manuel. «Tardes de enseñanza y parroquia: el adoctrinamiento de las niñas en la España franquista a través de las revistas bazar y tin tan (1947-1957)». El futuro del pasado 14 (2013), p. 230.

MenÉNDEZ PidAl, Ramón. Los españoles en la historia. Madrid, Espasa Calpe, 1947, p. 161.

MOLINERO, Carmen. «Silencio e invisibilidad: la mujer durante el primer franquismo». Revista de Occidente 223 (1999), pp. 63-82.

MORAGA, $\mathrm{M}^{a}$ Ángeles. «Notas sobre la situación jurídica de la mujer en el franquismo». Feminismo/s 12, diciembre (2008), p. 230.

NASH, Mary: «Mandato biológico y cometido social: la maternidad». En Thèbaud, F. (Dir.): Historia de las mujeres. El siglo XX, vol. V, Madrid, Taurus, 1993, pp. 688-703.

ORDEN MINISTERIAL del 1 de mayo de 1939, por la que se prohibió el sistema pedagógico de coeducación en las escuelas primarias.

PaYNe, Stanley. El régimen de Franco, 1936-1975. Cultura y vida cotidiana. Madrid, Síntesis, 1987, p. 134.

Pemartín, Julián. Teoría de la Falange. Madrid, Editora Nacional, 1942, p. 8.

PÉreZ DE URbel, Fray Justo. III Consejo Nacional de SF de FET y de las JONS, celebrado en las provincias de Zamora y León, 1939, SF de FET y de las JONS.

PRIMO DE Rivera, José Antonio. Obras completas: Discursos y escritos (1922-1936). Madrid, Instituto de estudios políticos, 1976, P. 1227. 
Primo de Rivera, Pilar. Discursos, Circulares y Escritos. Madrid, Gráficas Afrodisio Aguado, 1942, p. 7.

- Recuerdos de una vida. Madrid, Dyrsa, 1983, p. 279.

- XXVII Consejo Nacional de la SF en Logroño, mayo. Madrid, SF de FET y de las JONS, 1974, p. 4.

PUJADAS, Xavier: «Del barrio al estadio. Deporte, mujeres y clases populares en la Segunda República, 1931-1936, en PUJADAS, Xavier: Atletas y ciudadanos. Historia social del deporte en España 1870-2010, Madrid, Alianza Editorial, 2011, p. 152.

REGIDURÍA CENTRAL DE EDUCACIÓN FÍSICA. La actividad física y deportiva en la mujer. Madrid, Real Academia de la Historia, Archivo de la Asociación Nueva Andadura, carpeta 41, doc. 3.

Richmond, Kathleen. Las mujeres en el fascismo español. La Sección Femenina de la Falange, 1934-1959. Madrid, Alianza Ensayo, p. 235.

Rivero, Antonio. Deporte y modernización. Madrid, Comunidad de Madrid, 2003, p. 208.

SABín, José Manuel. La dictadura franquista (1936-1975). Textos y documentos, Madrid, Akal, 1997, p. 17.

SF DE FET Y DE LAS JONS. «Consigna». Medina, n 10, julio, 1941, p. 12.

— «Plan del ama de casa para 1941». Y, Madrid, SF de FET y de las JONS.

- Formación Político-Social. Primer curso de Bachillerato. Madrid, Delegación Nacional de la SF de FET y de las JONS, 1962, p. 67.

- Formación Político-Social. Quinto curso de Bachillerato. Madrid, SF de FET y de las JONS, 1965, p. 47.

- Historia y Misión. Madrid, SF de FET y de las JONS, 1951, p. 98.

- Oposiciones de Magisterio. Educación Física. Madrid, SF de FET y de las JONS, 1959 , p. 140.

SOUTHWORTH, H. R. «La propaganda católica y la guerra civil española». Historia 16, 4 (43), noviembre (1979), p. 71.

SuÁrez, Luis. Crónica de la Sección Femenina y su tiempo. Madrid, Asociación Nueva Andadura, p. 101.

TUÑón DE LARA, Manuel. Historia de España. Barcelona, Labor, 1988, p. 461.

TuSELl, Javier (Dir.). Historia de España, Vol. 2. Madrid, Taurus, (2001), p. 396.

VAllejo NÁGERA, Antonio. «Higiene psíquica de la raza», en Memoria resumen de las tareas científicas del I Congreso Nacional de Educación Física, Madrid, Jesús lópez, 1943, p. 243.

ZaVAla, José María. La pasión de Pilar Primo de Rivera. Barcelona, Plaza \& Janés, p. 430. 